\title{
Peran Orangtua terhadap Kesiapan Sekolah Taman Kanak- Kanak pada Anak Usia Dini
}

\author{
Sean Marta Efastri1 ${ }^{1}$, Suharni ${ }^{\otimes_{2}}$ \\ Pendidikan Anak Usia Dini, Universitas Lancang Kuning \\ DOI: $\underline{10.31004 / o b s e s i . v 5 i 1.454}$
}

\begin{abstract}
Abstrak
Penelitian ini bertujuan untuk mendeskripsikan peran orangtua terhadap kesiapan sekolah anak usia dini di TK Aisyiyah III Kecamatan Rumbai Pesisir Kota Pekanbaru. Masalah yang ditemukan dilapangan anak masih belum bisa mandiri, masih didampingi orangtua ketika berada disekolah dan dibantu oleh orangtua dalam mengerjakan tugas disekolah. Orangtua adalah hal terpenting didalam pertumbuhan dan perkembangan anak.Penelitian ini merupakan penelitian deskriptif. Untuk mengetahui tanggapan dari responden, teknik penelitian yang digunakan dalam penelitian ini adalah dengan menggunakan skala likert 4 . Hasil dari penelitian, orangtua sangat berperan penting dalam kesiapan sekolah anak yaitu bertanggungjawab terhadapan kesiapan sekolah anak, memotivasi, sebagai role model,sebagai pengawas dan sebagai konselor sehingga semua kebutuhan dalam kesiapan sekolah anak terpenuhi.
\end{abstract}

Kata Kunci: peran orangtua; kesiapan sekolah; anak usia dini.

\begin{abstract}
This study aims to deskription about the role of parents in early childhood school readiness in Aisyiyah III Kindergarten, Rumbai Pesisir District, Pekanbaru City. Problems found in the field of children are still not able to be independent, are still accompanied by parents when they are in school and assisted by parents in doing school work. Parents are the most important thing in a child's growth and development. This research is a descriptive study. To find out the responses of respondents, the research technique used in this study was to use a Likert scale 4 The results of research, parents are very important role in children's school readiness, namely being responsible for children's school readiness, motivating, as role models, as supervisors and as counselors so that all needs in school children's readiness are met.
\end{abstract}

Keywords: the role of parents; school readiness;earlychildhood.

Copyright (c) 2020 Sean Marta Efastri, Suharni

$\triangle$ Corresponding author :

Email Address : suharni@unilak.ac.id ( Pekanbaru Riau, Indonesia )

Received 31 January 2020, Accepted 29 April 2020, Published 25 July 2020 


\section{PENDAHULUAN}

Anak usia dini merupakan sosok yang unik artinya setiap anak memiliki karakteristik yang berbeda-beda. Optimalisasi perkembangan anak menjadi sebuah keniscayaan dan menjadi tanggung jawab orang dewasa, dalam hal ini adalah tanggung jawab orangtua. Pemberian perhatian lebih orangtua kepada anak juga merupakan sebuah keniscayaan (Fauziddin \& Mufarizuddin, 2018). Perkembangan anak dapat dioptimalisasi dengan pendidikan. Kusmitaningsih (2011) menyatakan seorang anak akan tumbuh dan berkembang dengan baik manakala memperoleh pendidikan yang paripurna (komprehensif).

Menurut Mansur (2005) pendidikan anak usia dini adalah suatu proses pembinaan tumbuh kembang anak dari lahir hingga enam tahun secara menyeluruh yang mencakup aspek fisik dan nonfisik dengan memberikan rangsangan bagi perkembangan jasmani, rohani (moral dan spitual), motorik, akal pikiran, emosional,dan sosial yang tepat agar anak tumbuh dan berkembang secara optimal. Anak harus distimulasi bukan hanya dari segi kognitif, tetapi fisik motorik, bahasa, sosial emosional dan moral agama, (Suryana, 2016).

Menurut Undang-undang Nomor 20 Tahun 2003 tentang Sistem Pendidikan Nasional Pasal 1 angka 14 menyatakan bahwa Pendidikan Anak Usia Dini (PAUD) adalah suatu upaya pembinaan yang ditujukan kepada anak sejak lahir sampai dengan usia enam tahun yang dilakukan melalui pemberian rangsangan pendidikan untuk membantu pertumbuhan dan perkembangan jasmani dan rohani agar anak memiliki kesiapan dalam memasuki pendidikan lebih lanjut (Nasional, 2003). Untuk itu anak harus memiliki kesiapan untuk memasuki pendidikan ke jenjang berikutnya dan membutuhkan partisipasi orang tua terhadap hal tersebut (Permono, 2013)

Kesiapan sekolah anak merupakan hal penting dalam menyiapkan anak sebelum memasuki jenjang pendidikan formal. Kesiapan bersekolah mulai diterapkan mulai dari pendidikan anak usia dini. Lembaga pendidikan anak usia dini merupakan suatu upaya pembinaan yang ditujukan mulai umur anak 3-6 tahun, mulai dari pemberian stimulasi untuk membantu pertumbuhan dan perkembangan sehingga anak memiliki kesiapan sekolah dalam menempuh pendidikan lebih lanjut (Maryatun, 2016). Setiap anak sudah distimulasi dengan berbagai rangsangan, otak kecilnya pun akan menyerap berbagai pengetahuan (Yulianti, 2014) dan anak akan distimulasi ketika memasuki lembaga PAUD.

Program pendidikan prasekolah memberikan manfaat jangka pendek maupun panjang seperti meningkatkan prestasi belajar, angka mengulang kelas rendah dan angka kenakalan yang lebih rendah. Faktor yang mendukung suksesnya kesiapan bersekolah, yaitu praktik pengasuhan orangtua, sosial ekonomi keluarga, kerjasama antara orangtua dan sekolah, usia anak, jenis kelamin, interaksi yang positif, konsep diri pada anak dan kesiapan sekolah, (Septiani et al., 2016).

Pendidikan pra sekolah atau lebih dikenal dengan pendidikan anak usia dini pada tahun 1990-an tidak banyak perbedaan dengan sekarang, selalu menarik perhatian para orangtua, masyarakat, maupun pemerintah sebagai pengambil keputusan. Pemerintah menyadari bahwa kualitas masa awal anak (early childhood) termasuk masa prasekolah merupakan cermin kualitas bangsa di masa yang akan datang, khususnya orangtua yang menyadari pentingnya hubungan orangtua, anak juga akan mewarnai hubungan anak dengan lingkungannya, (Ruhyana, 2018) Maka, diusia prasekolah merupakan masa yang sangat penting dalam mendidik anak usia dini bagi menghasilkan bangsa yang berkualitas dimasa akan datang. Dimasa prasekolah ini anak lebih mudah dibentuk dan distimulasi dalam berperilaku dan membentuk kepribadian yang baik.

Peneliti melakukan observasi pada anak-anak kelompok B4 di TK Aisyiyah III kecamatan Rumbai Pesisir, masih ada anak yang belum bisa di tinggal orangtua saat proses pembelajaran, anak kelompok $\mathrm{B} 4$ adalah usia $4-5$ tahun, masih ditemukan anak yang ditunggu orangtuanya sampai pulang sekolah, masih ada anak dibantu membukakan celana atau rok pasa saat ingin buang air kecil-besar, masih ada yang makan disuap dan juga masih ada anak yang selalu ditemani dalam pembelajaran dikelas. Hal tersebut bukan hanya menjadi 
permasalahan bagi guru tetapi juga pada orangtua tentunya, apalagi bagi orangtua yang bekerja sehingga hal tersebut merupakan suatu kendala dalam melakukan rutinitas. Teori ekologi sistem menjadi landasan berpikir penelitian khususnya yang terkait dnegan lingkungan mikrosistem. Hubungan baik antara orangtua dan guru secara,fisik, sosial maupun simbol mampu mempengaruhi perkembangan anak, (Bronfenbrenne, 1997). Namun, peran orangtua lebih menjadi prioritas dalam perkembangan dan pertumbuhan anak sehingga guru hanya menjadi scaffolding ketika berada di sekolah. Maka, peneliti melakukan penelitian untuk menganalisis peran orangtua terhadap kesiapan sekolah anak.

Sugiyono (2015) mengemukakan metode penelitian pada dasarnya merupakan cara ilmiah untuk mendapatkan data dengan tujuan dan kegunaan tertentu. Berdasarkan masalah umum penelitian ini, maka metode yang digunakan adalah metode deskriptif. Dan memaparkannya secara mendetail dan menganalisanya sehingga didapat gambaran yang utuh mengenai bentuk-bentuk, faktor-faktor yang mempengaruhi, dan dampak dari peran orangtua terhadap kesiapan sekolah anak usia dini tersebut. Penelitian ini digunakan untuk mengetahui bagaimana peran orangtua terhadap kesiapan sekolah anak usia dini di kelas B4 TK Aisyiyah III Kecamatan Rumbai Persisir.

\section{METODOLOGI}

Jenis penelitian yang dilakukan adalah penelitian kuantitatif dengan pendekatan deskriptif yaitu metode penelitian yang berlandasan pada filsafat positivisme, digunakan untuk meneliti populasi dan sampel tertentu, pengumpulan data menggunakan instrument penelitian, analisis data bersifat kuantitatif/statistik, dengan tujuan untuk menguji hipotesis yang telah diterapkan, (Sugiyono, 2012). Sampel adalah sebagian atau wakil populasi yang diteliti. Dinamakan penelitian sampel apabila kita bermaksud untuk menggeneralisasi hasil penelitian sampel.

Subjek penelitian adalah orangtua anak di TK Aisyiyah yang berjumlah 45 orang. Subjek penelitian merupakan objek atau subjek yang berada pada suatu wilayah dan memenuhi syarat-syarat tertentu berkaitan dengan masalah penelitian untuk mempelajari dan kemudian ditarik kesimpulan.

Analisis deskriptif digunakan untuk mendapatkan gambaran penyebaran data hasil penelitian masing-masing variable secara katagori. Melalui data empiris yang terkumpul diyakini akan dapat memberi jawaban permasalahan dalam penelitian ini. Skala likert digunakan untuk mengukur sikap, pendapat, dan persepsi seseorang atau sekelompok orang atau fenomenasosial. Metode yang digunakan dalam penarikan sampel ini adalah total sampling adalah teknik pengambilan sampel dimana jumlah sampel sama dengan populasi. Alasan menggambil total sampling jumlah populasi yang kurang dari 100. Sampel yang diambil dari penelitian ini adalah 45 . Keseluruhan populasi merupakan sampel pada penelitian ini.

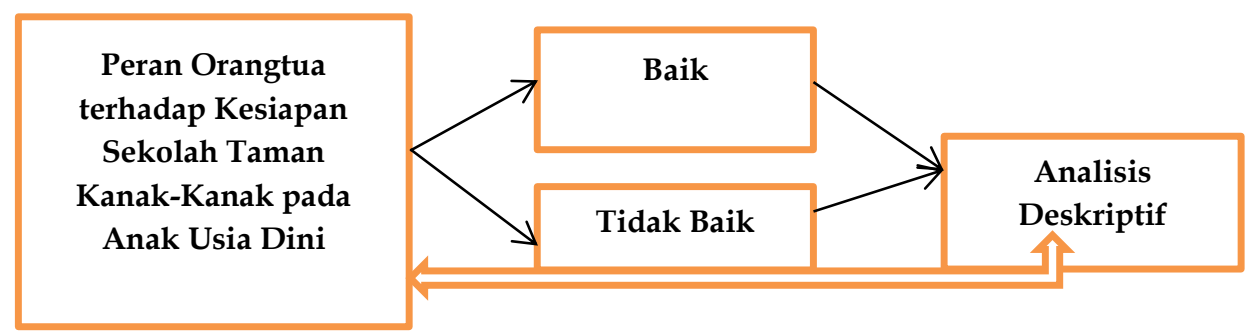

Gambar 1. Kerangka Pemikiran Penelitian

a. Untuk melihat bagaimana peran orantua dalam kesiapan sekolah anak, peneliti membuat empat kategori yang akan memperjelas peran orangtua dalam kesiapan sekolah anak menggunakan rumus interval menurut Hadi (2006:178) yakni : 
b. $I=\frac{N T-N R}{K}$

c. $I=\frac{100-0}{4}=25$

d. Keterangan :

e. I = Interval

f. $\quad$ NT $=$ Nilai Tertinggi

g. $\mathrm{NR}=$ Nilai Terendah

h. $\mathrm{K}=$ Kategori

i. Tabel berikut merupakan tabel kategori yang menjadi acuan untuk mendeskripsikan peran orangtua dalam kesiapan sekolah anak. Terdapat empat kategori pemahaman yaitu tidak baik, cukup baik, baik dan sangat baik.

\section{HASIL DAN PEMBAHASAN}

Dari hasil penelitian yang dilakukan oleh peneliti melalui wawancara dan menggunakan angket, pada indikator pertama yaitu tanggung jawab diperoleh skor 88 dengan kategori sangat baik, secara keseluruhan orangtua bertanggungjawab dalam menyiapkan anak dalam memulai dunia sekolah. Pada indikator kedua yaitu motivasi diperoleh skor 70 dengan kategori baik, orangtua juga memberikan motivasi kepada anak agar anak memulai memasuki prasekolah. Namun pada indikator ketiga yaitu social modeling masih rendah dengan skor 65,45 dengan kategori cukup baik. Indikator keempat yaitu panutan dengan skor 70,70 pada kategori cukup baik, indikator kelima yaitu pengawasan dengan skor 70,10 pada kategori baik, dan indikator keenam yaitu konselor dengan skor 65 pada kategori cukup baik.

Berdasarkan hasil pengolahan data yang telah dilakukan didapat hasil sebagai berikut:

Tabel 5.1. Rekapitulasi Peran Orangtua Terhadap Kesiapan Sekolah Anak di Taman Kanak-kanak

\begin{tabular}{clcl}
\hline No. & \multicolumn{1}{c}{ Indikator } & Persentase & \multicolumn{1}{c}{ Kategori } \\
\hline $\mathbf{1}$ & Tanggungjawab & 88,00 & Sangat Baik \\
& & & \\
\hline $\mathbf{2}$ & Motivasi & 70,00 & Baik \\
\hline $\mathbf{3}$ & Social Modelling & 65,45 & Cukup Baik \\
\hline $\mathbf{4}$ & Panutan & 70,70 & Baik \\
\hline $\mathbf{5}$ & Pengawasan & 70,10 & Baik \\
\hline $\mathbf{6}$ & Konselor & 65,00 & Cukup Baik \\
\hline
\end{tabular}

Hasil yang diperoleh dari penelitian adalah orangtua berperan penting bukan hanya dirumah tapi ikut andil dalam perkembangan anak disekolah sehingga orangtua mengetahui perkembangan anak dan menstimulasi bukan hanya kemandirian tetapi semua aspek yang berhubungan dengan kesiapan sekolah anak. Dapat dilihat bahwa bermacam aspek seperti tanggungjawab, motivasi,social modeling,panutan,pengawasan dan konselor saling berhubungan. Orangtua memegang peranan dalam memikul tanggungjawab seperti memberikan materi maupun nonmateri. Anak juga membutuhkan motivasi yang tinggi dari orangtua karena dengan motivasi yang baik haruslah dari keluarga terlebih dahulu baru kelingkungan luar. Sebelum anak kesekolah orangtua sudah seharusnya memberikan dukungan sehingga anak lebih bersemangat dalam memasuki dunia sekolah. Selain itu orangtua merupakan social modeling dalam keluarga sehingga rata-rata anak bercita-cita menjadi sosok orangtua mereka. Mereka belum mempunyai bayangan yang lebih sehingga orangtua harus menunjukkan perilaku yang baik agar menjadi panutan kepada anak.

Peran pengawasan orangtua terhadap anak tidak lepas walaupun anak tidak berada dirumah. Orangtua tetap harus memantau kegiatan yang dilakukan oleh anak dirumah maupun diluar sekolah. Dan terakhir orangtua berperan sebagai konselor terbaik bagia anak karena tugas orangtua yang baik memberikan nasehat, menegur anak ketika melakukan 
kesalahan dan memberikan solusi yang baik ketika anak berada dalam kondisi yang tidak nyaman seperti ketidaksiapan dalam memasuki lingkungan yang baru dan cara beradaptasi.

Gambaran umum responden menunjukkan identitas responden. Responden pada penelitian ini adalah guru TK Aisyiyah III kecamatan Rumbai Pesisir Pekanbaru. Karakteristik responden yang disajikan berupa jenis kelamin, umur, pendidikan dan masa kerja. Dalam penelitian ini peneliti memiliki 45 responden yang dianggap layak dan sesuai kriteria penelitian.

Pada peneltian ini beberapa aspek indikator yang diamati tentang peran orangtua dalam kesiapan sekolah anak yaitu ; a) tanggungjawab orangtua, b) motivasi, c) sosial modeling, d) panutan, e) pengawasan, dan f) konselor.

Berdasarkan pendapat Hughes et al. (2018) aspek bahasa meliputi kemampuan bahasa anak sudah mencapai tingkat sesuai perkembangannya, yaitu anak mampu berkomunikasi dan memahami apa yang dikomunikasikan oleh orang lain. Sedangkan menurut Endang aspek kesiapan sekolah terdiri kosentrasi, berbahasa, mengenal konsep,motoric,menyamakan bentuk,daya ingat dan menggambar orang. Penelitian yang dilakukan oleh Denham (2006) mengenai kemampuan sosial-emosional sebagai dukungan kesiapan bersekolah, menegaskan bahwa kesiapan belajar seorang anak ditunjukkan dari ekspresi emosi yang positif, antusiasme, dan kemampuan untuk mengendalikan emosi dan perilaku. Oleh karena itu, kesiapan secara sosial-emosional juga perlu diperhatikan dalam meningkatkan kesiapan anak untuk bersekolah, (Nurjannah, 2017).

Peran orangtua dan guru saling mendukung dalam kesiapan sekolah anak. Dari indikator tanggungjawab, orangtua mempunyai tanggungjawab yang besar dalam mempersiapkan anak bersekolah, (Nurmasita \& Rofiah, 2018). Indikator pertama yang dinilai yaitu tanggungjawab orangtua yang dinilai termasuk kategori sangat baik. Dari hasil wawancara dan kuesioner yang dilakukan orangtua sudah memenuhi kriteria yang bertanggungjawab. Rozalena \& Kristiawan (2017) mengemukakan orangtua yang bertanggungjawab lebih menunjukkan respon dan kerjasama yang baik dengan guru disekolah. Selain itu motivasi dari orangtua merupakan indikator yang sangat penting dalam persiapan sekolah anak, (Kiuru et al., 2012). Anak yang termotivasi dari orangtua cenderung lebih bersemangat dan secara sosial emosional lebih baik dibandingkan dengan anak yang tidak mendapat motivasi dari orangtuanya.

Peran orangtua sangat berdampak pada kesiapan sekolah anak sehingga orangtua harus lebih banyak memberikan motivasi dan memberikan stimulasi dari berbagai aspek dalam kesiapan sekolah, (Aslan, 2019). Selain itu, guru juga ikut andil dalam kesiapan sekolah anak sehingga terjadi kerjasama antara orangtua dan guru.

Havighurst et al. (2010) menyarankan orangtua untuk menempatkan diri sebagai emotional coaching parent. Konsep dasar dari emotional coaching parentini adalah menyadari ungkapan emosi anak, membangun koneksi, mendengarkan dengan seksama,membantu anak menamai emosi, menetapkan batasan dan menyelesaikan masalah, (Gottman, 1998). Penelitian yang dilakukan oleh (Denham, 2006), mengenai kemampuan sosial-emosional sebagai dukungan kesiapan bersekolah, menegaskan bahwakesiapan belajarseorang anak ditunjukkan dari ekspresi emosi yang positif, antusiasme, dankemampuan untuk mengendalikan emosi dan perilaku, (Palmier-Claus et al., 2016). Oleh karena itu, kesiapan secara sosial-emosional juga perlu diperhatikan dalam meningkatkan kesiapan anak untuk bersekolah.

Sosial Modelling orangtua juga dilihat terhadap persiapan sekolah anak. Sebagai model bagi anaknya, orangtua dapat secara langsung menunjukkan bagaimana cara berkomunikasi yang baik dengan berkomunikasi dengan anaknya. Ketika orangtua tidak dapat berkomunikasi dengan anak-anak mereka, mereka akan kesulitan untuk menyampaikan nilainilai, keyakinan, pemahaman, atau kebijaksanaan tentang bagaimana cara mengatasipermasalahan yang dialami, (Novrinda, 2017). 
Orangtua juga merupakan panutan bagi anak sehingga apa yang menjadi kebiasaan orangtua dari segi positif maupun negatif menjadi panutan anak. Maka dari itu, orangtua harus menunjukkan perilaku dan contoh yang baik bagi anak. Pada indikator pengawasan, orangtua harus melakukan pengawasan dari segi pertumbuhan dan perkembangan anak sehingga semua perubahan pada diri anak terpantau oleh orangtua, (Vani et al., 2014). Orangtua tua harus tetap mengawasi setiap kegiatan yang dilakukan anak dalam pembelajaran, contohnya orangtua akan memeriksa pembelajaran anak dirumah sehingga orangtua tau apa saja yang dilakukan oleh anak disekolah. Terakhir orangtua merupakan konselor untuk anak karena ketika terjadi komunikasi yang nyaman antara orangtua dan anak, anak akan lebih mudah menceritakan apa yang terjadi pada diri anak pada orangtua, (Agustin, 2014). Ketika orangtua dapat menjalin komunikasi yang baikdengan anak, khususnya dalam situasi-situasi konflik, hubungan orangtua-anak bisa menjadisemakin erat. Selain itu, orangtua juga dapat mengajari anak cara merespons konflik yangterjadi secara lebih baik.

\section{SIMPULAN}

Kesiapan orangtua saat anak memasuki sekolah pada Kelompok 4 TK Aisyiyah III sudah dilaksanakan secara maksimal, walaupun masih ada beberapa dari indikator peran orangtua yang pada kategori kurang baik. Faktor penyebab kurangnya kesiapan sekolah anak adalah orangtua sibuk dalam pekerjaan sebagai pegawai swasta berdampak terhadap kurangnya motivasi, dukungan dan perhatian dari orangtua dalam kesiapan sekolah anak. Orangtua menyerahkan tanggungjawab kepada guru sehingga orangtua berasumsi orangtua tidak mempunyai peran yang penting dalam kesiapan sekolah anak. Padahal peran orantua lebih besar dibandingkan peran guru. Guru yang hanya mendidik anak ketika berada disekolah.

\section{UCAPAN TERIMAKASIH}

Ucapan terima kasih kepada Universitas Lancang Kuning yang telah mendanai penelitian ini dengan skim apbf. Diharapkan penelitian ini dapat memberikan manfaat untuk institusi dan masyarakat.

\section{DAFTAR PUSTAKA}

Agustin, M. (2014). Hakikat Bimbingan dan Konseling untuk Anak Usia Dini. Modul.

Aslan, A. (2019). Peran Pola Asuh Orangtua di Era Digital. Jurnal Studia Insania. https:// doi.org/10.18592/jsi.v7i1.2269

Bronfenbrenne, M. (1997). Growth and Recessions in Japan. Japanese Economy. https:// doi.org/10.2753/jes1097-203×250391

Denham, S. A. (2006). Social-emotional competence as support for school readiness: What is it and how do we assess it? Early Education and Development. https:// doi.org/10.1207/s15566935eed1701_4

Fauziddin, M., \& Mufarizuddin, M. (2018). Useful of Clap Hand Games for Optimalize Cogtivite Aspects in Early Childhood Education. Jurnal Obsesi : Jurnal Pendidikan Anak Usia Dini, 2(2), 162. https:/ / doi.org/10.31004/obsesi.v2i2.76

Gottman, J. M. (1998). PSYCHOLOGY AND THE STUDY OF MARITAL PROCESSES. Annual Review of Psychology. https:// doi.org/10.1146/annurev.psych.49.1.169

Havighurst, S. S., Wilson, K. R., Harley, A. E., Prior, M. R., \& Kehoe, C. (2010). Tuning in to Kids: Improving emotion socialization practices in parents of preschool childrenfindings from a community trial. Journal of Child Psychology and Psychiatry and Allied Disciplines. https://doi.org/10.1111/j.1469-7610.2010.02303.x

Hughes, J., Morrison, L., \& Dobos, L. (2018). Re-making teacher professional development. Studies in Health Technology and Informatics. https:/ / doi.org/10.3233/978-1-61499-9232-602 
Kiuru, N., Aunola, K., Torppa, M., Lerkkanen, M. K., Poikkeus, A. M., Niemi, P., Viljaranta, J., Lyyra, A. L., Leskinen, E., Tolvanen, A., \& Nurmi, J. E. (2012). The role of parenting styles and teacher interactional styles in children's reading and spelling development. Journal of School Psychology. https://doi.org/10.1016/j.jsp.2012.07.001

Kusmitaningsih, W. (2011). Pengelolaan Pembelajaran Nilai-Nilai Agama Islam pada Pendidikan Anak Usia Dini (PAUD) Aisyiyah Kreatif di Kota Magelang. Universitas Muhammadiyah Surakarta.

Mansur. (2005). Pendidikan Anak Usia Dini dalam Islam. In At-Taqaddum. https://doi.org/10.1016/j.supflu.2008.07.002

Maryatun, I. B. (2016). PERAN PENDIDIK PAUD DALAM MEMBANGUN KARAKTER ANAK. Jurnal Pendidikan Anak. https:// doi.org/10.21831/jpa.v5i1.12370

Nasional, D. P. (2003). Undang-Undang Nomor 20 Tahun 2003, Tentang Sistem Pendidikan Nasional. In Depdiknas. https:// doi.org/10.35362/rie280958

Novrinda, N. kurniah dan Y. (2017). Peran Orangtua Dalam Pendidikan Anak Usia Dini, Ditinjau Dari Latar Belakang Pendidikan. Universitas Negeri Bengkulu. https:// doi.org/10.33369/jip.2.1.39-46

Nurjannah, N. (2017). Mengembangkan Kecerdasan Sosial Emosional Anak Usia Dini melalui Keteladanan. Hisbah: Jurnal Bimbingan Konseling Dan Dakwah Islam, 14(1), 5061. https:// doi.org/10.14421/hisbah.2017.141-05

Nurmasita, N., \& Rofiah, N. H. (2018). PERAN ORANGTUA DALAM PENANAMAN TANGGUNGJAWAB PADA SISWA SD MUHAMMADIYAH AMBARKETAWANG 2 GAMPING. Jurnal Fundadikdas (Fundamental Pendidikan Dasar). https:/ / doi.org/10.12928/fundadikdas.v1i1.72

Palmier-Claus, J., Berry, K., Darrell-Berry, H., Emsley, R., Parker, S., Drake, R., \& Bucci, S. (2016). Childhood adversity and social functioning in psychosis: Exploring clinical and cognitive mediators. Psychiatry Research. https://doi.org/10.1016/j.psychres.2016.02.004

Permono, H. (2013). Peran Orangtua dalam Optimalisasi Tumbuh Kembang Anak untuk Membangun Karakter Anak Usia Dini. Universitas Muhammadiyah Surakarta. http:// publikasiilmiah.ums.ac.id/handle/11617/3994

Rozalena, \& Kristiawan, M. (2017). Pengelolaan Pembelajaran Paud Dalam Mengembangkan Potensi Anak Usia Dini. JMKSP (Jurnal Manajemen, Kepemimpinan, Dan Supervisi Pendidikan), 2(1), 76-86.

Ruhyana, N. F. (2018). AKSESIBILITAS ANAK MENGIKUTI PENDIDIKAN ANAK USIA DINI DI KABUPATEN SUMEDANG. JIV-Jurnal Ilmiah Visi. https://doi.org/10.21009/jiv.1302.4

Septiani, R., Widyaningsih, S., \& Igohm, muhammad K. B. (2016). Tingkat Perkembangan Anak Pra Sekolah Usia 3-5 Tahun Yang Mengikuti Dan Tidak Mengikuti Pendidikan Anak Usia Dini (Paud). Jurnal Keperawatan Jiwa.

Sugiyono. (2012). Metode Penelitian Kuantitatif, Kualitatif dan R \& D.Bandung:Alfabeta. Metode Penelitian Kuantitatif, Kualitatif Dan R E D.Bandung:Alfabeta. https:// doi.org/10.1017/CBO9781107415324.004

Sugiyono. (2015). Metode Penelitian. Metode Penelitian.

Suryana, D. (2016). PENDIDIKAN ANAK USIA DINI Stimulasi dan Aspek Perkembangan Anak. Kencana.

Vani, G. C., Raharjo, S. T., Hidayat, E. N., \& Humaedi, S. (2014). PENGASUHAN (GOOD PARENTING) BAGI ANAK DENGAN DISABILITAS. Share : Social Work Journal, 4(2). https://doi.org/10.24198/share.v4i2.13067

Yulianti, T. R. (2014). Peranan Orang Tua dalam Mengembangkan Kreativitas Anak Usia Dini. Jurnal Empowerment, 4(1), 11-24. http://ejournal.stkipsiliwangi.ac.id/index.php/empowerment/article/view/569 